\title{
Does patient self-management education of primary care professionals improve patient outcomes: a systematic review
}

\author{
Andree Rochfort ${ }^{1}$, Sinead Beirne ${ }^{1}$, Gillian Doran ${ }^{1}$, Patricia Patton ${ }^{1}$, Jochen Gensichen², Ilkka Kunnamo3 , \\ Susan Smith ${ }^{4}$, Tina Eriksson ${ }^{5}$ and Claire Collins ${ }^{1 *}$ (D)
}

\begin{abstract}
Background: Patient self-management support is recognised as a key component of chronic care. Education and training for health professionals has been shown in the literature to be associated with better uptake, implementation and effectiveness of self-management programs, however, there is no clear evidence regarding whether this training results in improved health outcomes for patients with chronic conditions.

Methods: A systematic review was undertaken using the PRISMA guidelines using the Cochrane Library, PubMEd, ERIC, EMBASE, CINAHL, PsycINFO, Web searches, Hand searches and Bibliographies. Articles published from inception to September 1st, 2013 were included. Systematic reviews, Meta-analysis, Randomized controlled trials (RCTs), Controlled clinical trials, Interrupted time series and Controlled before and after studies, which reported on primary care health professionals' continuing education or evidence-based medicine/education on patient self-management for any chronic condition, were included. A minimum of two reviewers participated independently at each stage of review.

Results: From 7533 abstracts found, only two papers provided evidence on the effectiveness of self-management education for primary healthcare professionals in terms of measured outcomes in patients. These two articles show improvement in patient outcomes for chronic back pain and diabetes based on RCTs. The educational interventions with health professionals spanned a range of techniques and modalities but both RCTs included a motivational interviewing component.

Conclusions: Before and up to 2 years after the incorporation of patient empowerment for self-management into the WONCA Europe definition of general practice, there was a scarcity of high quality evidence showing improved outcomes for patients as a result of educating health professionals in patient self-management of chronic conditions.
\end{abstract}

Keywords: Self-management, Patient empowerment, Primary care, Chronic conditions

\section{Key messages}

Despite a vast literature on the topic of patient self-management, evidence on the association between training of health professionals in patient self-management with measured patient health outcomes was rare prior to and up to 2 years after its incorporation into the WONCA Europe definition of general practice.

However, the limited available evidence suggests that specific training programmes for primary care health professionals (a) may improve and support patient

* Correspondence: claire.collins@icgp.ie

1'Irish College of General Practitioners, 4-5 Lincoln Place, Dublin 2, Ireland

Full list of author information is available at the end of the article competencies for self-management and (b) may improve quality of life for patients with chronic conditions.

\section{Background}

The European Definition of General Practice by the World Organization of National Colleges, Academies and Academic Associations of General Practitioners/Family Physicians (WONCA) in the European Region, lists 12 characteristics within six core competencies to define the activities of general practice / family medicine (GP/FM) [1]. The twelfth characteristic of general practice "Promotion of patient empowerment and self-management" was officially approved in 2011 [1]. It follows therefore, that

(c) The Author(s). 2018 Open Access This article is distributed under the terms of the Creative Commons Attribution 4.0 International License (http://creativecommons.org/licenses/by/4.0/), which permits unrestricted use, distribution, and reproduction in any medium, provided you give appropriate credit to the original author(s) and the source, provide a link to the Creative Commons license, and indicate if changes were made. The Creative Commons Public Domain Dedication waiver (http://creativecommons.org/publicdomain/zero/1.0/) applies to the data made available in this article, unless otherwise stated. 
European family physicians agree that among the various disciplines of medicine, GP/FM has a key role in harnessing patient autonomy to develop their expertise in managing their own health and wellness [2].

Promoting patient self-management (PSM) in the European definition of General Practice is listed under the core competency of "Patient-centered care", in keeping with scientific evidence on patient empowerment within general practice [3]. The concept of patient empowerment for patient self-management in chronic conditions has been further explored by the European Society for Quality and Safety in General Practice (EQuiP) [4].

The World Health Organisation (WHO) defines chronic conditions as those that encompass disability and disease that people 'live with' for extended periods of time [5]. They include non-communicable diseases (NCD), such as cardiovascular diseases, cancers, respiratory diseases and diabetes, and are associated with lifestyle factors and patient behaviours and account for $70 \%$ of deaths globally (40 million deaths) in 2017 [6]. By 2030, the total annual number of NCD deaths is projected to increase to 52 million per year [6]. This escalation of the prevalence of chronic conditions is a significant factor in the increasingly heavy workload in family medicine internationally, which is also increasing in complexity as people live longer often with multiple co-existing chronic conditions.

By definition, chronic disease is not reversible or curable [6]. The Chronic Care Model (CCM) [7] is an internationally accepted model for the management of NCD and specifies self-management support as a key component. Patient self-management can be described as " $a$ set of tasks and processes that are used by a patient to maintain wellness in the presence of an ongoing illness [8] and it may also encompass prevention..." [9]. In addition to knowledge of the disease and treatment options, patient self-management "involves active involvement in decision making, coping with signs and symptoms of disease, making lifestyle changes and managing the impact of the disease on life" [10].

The benefits of supporting patients to implement and maintain self-management skills have been shown to improve patients' self-care and more appropriate utilisation of health services [11-13]. Improved patient self-management can also reduce health care costs through fewer outpatient visits [14-17] and fewer hospital admissions [18-20]. Lifestyle interventions by patients have been shown to have clinical benefit in a wide range of conditions such as diabetes, coronary heart disease, heart failure, and rheumatoid arthritis [21].

In the Chronic Care Model, achieving optimum outcomes for patients requires a productive interaction between "an informed activated patient and a prepared proactive practice team" [22]. Many studies focus on the role of patient education in self-management, yet no systematic reviews are published on whether clinician education to improve patient self-management has an effect on patient outcomes. A preliminary literature review [23] indicated that effective patient self-management support would require specific training of primary care health professionals. Education and training have been identified as a potential way of engaging primary care clinicians in patient self-management support [24]. However, though existing studies suggest that health professional training is associated with better uptake and implementation of patient self-management programs $[9,14,25,26]$, it is not clear which type of professional training this might involve, or whether it actually improved patient outcomes.

The primary aim of this systematic review was to examine the effectiveness of educational interventions for primary care professionals that are designed to improve their support for patient self-management of chronic conditions and improve patient outcomes. The timeframe was specifically chosen in order to establish if this evidence was available prior to and up to 2 years after the concept of patient empowerment for self-management was introduced into the WONCA Europe definition of general practice. Furthermore, this systematic review was used to inform the subsequent project work packages, which included the creation of an online educational module and its evaluation.

\section{Methods}

A systematic review was undertaken using the PRISMA guidelines [27] and follows the methodology outlined in the PROSPERO registered protocol (Database registration number: CRD42013004418) [28].

\section{Sourcing information}

Two specialist subject librarians assisted in the development of the search strategy designed to identify internationally recognised terminology in peer-reviewed journals. Full details of this strategy are available in the published protocol [28]. Six databases were searched Cochrane Library, PubMed, ERIC, EMBASE, CINAHL and PsycINFO - in addition to Web searches, Hand searches and Bibliographies. Articles published in advance of September 1st, 2013 were included in the review, with the search conducted by GD and PP. The full search terms and sample search are shown in 'Additional file 1'. The timeframe was deliberately chosen in order to coincide with the inclusion of the concept of patient empowerment in WONCA Europe's definition of general practice. It was also the first work package of a larger project. It is intended to repeat the systematic review in 2018. 


\section{Selection criteria}

Studies with the following designs were included: systematic reviews, randomized controlled trials (RCTs), controlled clinical trials, interrupted time series, and controlled before and after studies.

Participants were physicians in primary care settings, other clinicians in primary care settings and patients 18 + years with chronic conditions in primary care settings. Included interventions had an educational focus designed to train primary care clinicians to support patient self-management. This review was concerned with all chronic conditions as they occur generically in the primary care setting, rather than focusing on any one specific chronic condition. Only articles including reference to patient outcomes, measured using validated measurement scales, were included. The primary patient outcome was change in patients' self-management behaviours; the secondary outcomes were changes in physical health measures, health behaviours including medical adherence and compliance, service utilisation, psychological health, psycho-social function (e.g. Quality of Life, SF36, SF12) physical functioning and knowledge.

The eligibility of studies was determined using the inclusion and exclusion criteria listed in the registered proposal and shown in Table 1.

\section{Data extraction}

All abstracts were reviewed using the RefWorks package to categorise the abstracts identified by the search. The initial review of abstracts was undertaken by SB with $10 \%$ of same re-checked by AR. The full text articles of all those considered to be of possible relevance to the systematic review were read independently by SB, JG and $C C$ and categorised using the same exclusion reasons. Disagreements were reviewed by AR. The final list of full text articles were then reviewed by JG to confirm relevance. The quality assessment and extraction of thematic content of the final list of articles applicable to the systematic review question were considered by $\mathrm{CC}$ and AR.

\section{Quality assessment}

We assessed risk of bias and overall quality of individual studies using the Quality of Assessment Tool for Quantitative Studies [29] (Tables 2, 3 and 4). For each study, reviewers rated six components (selection bias, study design, confounders, blinding, data collection methods, and withdrawals and dropouts) leading to an overall methodological quality rating for each study of strong, moderate, or weak, with strong quality indicating a low risk of bias. Reviewers resolved rating disagreements through discussion.

\section{Data synthesis}

We performed a narrative data synthesis as the clinical heterogeneity and differences in outcomes in the two studies meant meta-analysis would have been inappropriate.

\section{Results}

\section{Study review and selection}

Overall 7533 abstracts were reviewed following removal of duplicates from the database and hand/web searches; of these, 43 full text articles were retrieved and read

Table 1 Inclusion and exclusion criteria

\begin{tabular}{|c|c|c|}
\hline Inclusion Criteria & Exclusion Criteria & $\begin{array}{l}\text { Exclusion } \\
\text { code }\end{array}$ \\
\hline English papers & Non- English papers & Eng \\
\hline Adults $(18+)$ & Study population $<18$ & Age \\
\hline Primary Care/Community & Secondary Care/Hospital & Not PC \\
\hline $\begin{array}{l}\text { Chronic conditions, chronic illness, chronic disease, non-communicable } \\
\text { disease (NCD) }\end{array}$ & Acute conditions & Acute \\
\hline $\begin{array}{l}\text { Study Type- Systematic reviews, meta- analysis, RCTs, controlled clinical } \\
\text { trials, interrupted time series. Controlled before and after studies }\end{array}$ & $\begin{array}{l}\text { Study Type- Qualitative studies, populations studies, surveys, } \\
\text { cross sectional, uncontrolled before and after studies (cohort) }\end{array}$ & Study \\
\hline \multirow{4}{*}{$\begin{array}{l}\text { Education and training of primary care Health Professionals for patient } \\
\text { education in promoting change, behaviour change, lifestyle change, } \\
\text { patient engagement, patient empowerment, motivational skills, patient } \\
\text { collaboration, patient adherence and compliance, Patient self- } \\
\text { management, decision making, patient problem- solving }\end{array}$} & Not education/training of health care professionals & Int \\
\hline & Not primary care health professionals & Pop \\
\hline & Primary outcome measures not included & Out \\
\hline & Direct patient education only & Edu \\
\hline $\begin{array}{l}\text { Continuing education / CME / Lifelong learning / Evidence based } \\
\text { medicine }\end{array}$ & Guideline adherence, clinical performance & Guid \\
\hline \multirow[t]{3}{*}{ All studies published to September 2013} & Organisational interventions & Org \\
\hline & Financial changes and incentives & $\mathrm{Fi}$ \\
\hline & Regulatory interventions & Reg \\
\hline
\end{tabular}


Table 2 Risk of bias

\begin{tabular}{|c|c|c|}
\hline Bias & Becker et al. [30] & Rubak et al. [31] \\
\hline $\begin{array}{l}\text { Random sequence generation } \\
\text { (selection bias) }\end{array}$ & Low - Selection by central permuted block randomisation & Low - Selection by drawing lots \\
\hline $\begin{array}{l}\text { Allocation Concealment } \\
\text { (selection bias) }\end{array}$ & Low & Unclear-Insufficient information provided \\
\hline $\begin{array}{l}\text { Blinding of participants } \\
\text { and personnel } \\
\text { (performance bias) }\end{array}$ & $\begin{array}{l}\text { High - Blinding of participants and personnel was not } \\
\text { possible }\end{array}$ & $\begin{array}{l}\text { High - Blinding of participants and personnel } \\
\text { was not possible }\end{array}$ \\
\hline $\begin{array}{l}\text { Blinding of outcome } \\
\text { assessment } \\
\text { (detection bias) }\end{array}$ & High - Self-reported outcomes & High - Self-reported outcomes \\
\hline $\begin{array}{l}\text { Incomplete outcome } \\
\text { data (attrition bias) }\end{array}$ & Low - Clear participant flow reported & Low - Clear participant flow reported \\
\hline $\begin{array}{l}\text { Selective reporting } \\
\text { (reporting bias) }\end{array}$ & $\begin{array}{l}\text { Low - The published report includes all expected } \\
\text { outcomes }\end{array}$ & $\begin{array}{l}\text { Low - The published report includes all expected } \\
\text { outcomes }\end{array}$ \\
\hline Other bias & $\begin{array}{l}\text { Unclear - but unlikely. Insufficient information } \\
\text { to assess whether another important risk of bias exists }\end{array}$ & $\begin{array}{l}\text { Unclear - but possible; no baseline data. Insufficient } \\
\text { information to assess whether another important risk } \\
\text { of bias exists }\end{array}$ \\
\hline
\end{tabular}

(Fig. 1). Following this second stage review, only two articles that reported patient outcomes were included in the systematic review.

The two papers were both RCTs of educational interventions in primary care health professionals and examined their impact on patient outcome measures (Table 5).

The primary outcome of this review is the effectiveness of educational interventions in terms of patient outcomes. Our results show that education and skills training of primary care health professionals may improve patient performance of self-management activities, improve patient lifestyle behaviours, and patient self-efficacy in making behaviour changes. These changes were associated with improved perception of quality of life.

Becker et al. [30] compared outcomes of three groups of patients with low back pain from one control group of several practices and two intervention groups. The control group comprised of 43 practices with 410 patients and received printed educational information alone. One intervention group received education on guideline implementation (GI) alone (37 practices, 479 patients) and the other intervention group received GI plus training in motivational interviewing techniques (MIT) (38 practices, 70 practice nurses, 489 patients). Both intervention group patients showed significant improvements in functional capacity at six months though there was no difference at 12 months. Patients of the clinicians in the motivational interviewing group showed significant improvement in functional capacity after six months with a greater number of patients reporting pain free days (less permanent pain) after six months and after 12 months. These same patients also demonstrated a significant improvement in quality of life scale, having received one session from a practice nurse trained in motivational interviewing. The control group demonstrated no improvement in functional capacity, no perceived improvement in quality of life and they reported greater levels of permanent pain compared to both intervention groups.

Rubak et al. [31] included 65 GPs from 48 practices and all GPs attended a half day course on intensive treatment of type-2 diabetes. Practices were then randomised into control and intervention groups and the intervention group had an additional one and a half day residential course for 29 GPs from 21 practices (137 patients) on motivational interviewing techniques. The intervention practices also had a half day follow up course on MIT, twice during the following one year. The patients of the intervention group clinicians were shown to be more motivated to change behaviours and significantly more autonomous in their choice of actions leading to behavioural changes than patients of the control clinicians. The patients of the intervention clinicians also reported having received significantly more specific advice from their GP regarding diet, exercise and self-control of diabetes, and they also reported receiving significantly more counselling re smoking cessation. Intervention group patients reported an increase in their awareness of the importance of taking control of their own specific risk factors for diabetes. This study also reported a significant improvement in self-efficacy between pre-training and post training for all primary care health professionals undergoing motivational interviewing training.

\section{Discussion}

\section{Main findings}

The key finding of this systematic review is the scarcity of studies that assess the impact on patient outcomes of training primary care clinicians in patient self-management of chronic conditions. This was surprising given that patient 
Table 3 Quality assessment using EPHPP tool

\begin{tabular}{|c|c|c|}
\hline Component & Becker et al. [30] & Rubak et al. [31] \\
\hline $\begin{array}{l}\text { Selection Bias 1. Are the individuals selected to participate likely to } \\
\text { be representative of the target populations? }\end{array}$ & Can't tell $=4$ & Can't tell $=4$ \\
\hline $\begin{array}{l}\text { Selection Bias 2. What percentage of the selected individuals } \\
\text { agreed to participate? }\end{array}$ & Less than $60 \%$ agreement $=3$ & Can't tell = 5 \\
\hline SELECTION BIAS RATING & WEAK & WEAK \\
\hline Study design & Randomized control trial = 1 & Randomized control trial $=1$ \\
\hline Was the study described as randomized? & Yes & Yes \\
\hline Was the method of randomization described? & Yes & Yes \\
\hline Was the randomization process appropriate? & Yes & Yes \\
\hline Study design rating & Strong & Strong \\
\hline $\begin{array}{l}\text { Were there important differences between groups prior } \\
\text { to the intervention? }\end{array}$ & $\mathrm{No}=2$ & $\mathrm{No}=2$ \\
\hline What percentage of relevant confounders were controlled? & N/A & N/A \\
\hline Confounders rating & Strong & Strong \\
\hline $\begin{array}{l}\text { Were the outcome assessors aware of the intervention status } \\
\text { of participants? }\end{array}$ & Can't tell $=3$ & Can't tell = 3 \\
\hline Were the participants aware of the research question? & $\mathrm{No}=2$ & $\mathrm{No}=2$ \\
\hline Blinding rating & Moderate & Moderate \\
\hline Were data collection tools shown to be valid? & Yes $=1$ & Yes $=1$ \\
\hline Were data collections tools shown to be reliable? & Yes $=1$ & Yes $=1$ \\
\hline Data collection rating & Strong & Strong \\
\hline Were withdrawals and drop-outs reported in terms of numbers/reasons? & Yes $=1$ & Yes $=1$ \\
\hline Percentage of participants completing the study & $80=-100 \%=1$ & $80=-100 \%=1$ \\
\hline Withdrawals and drop outs rating & Strong & Strong \\
\hline $\begin{array}{l}\text { Intervention Integrity: } \\
\text { What percentage of participants received the allocated } \\
\text { intervention? }\end{array}$ & $80=-100 \%=1$ & $80=-100 \%=1$ \\
\hline Was the consistency of the intervention measured & Can't tell $=3$ & Can't tell = 3 \\
\hline $\begin{array}{l}\text { Is it likely that subjects received an unintended intervention } \\
\text { that may influence results? }\end{array}$ & $\mathrm{No}=5$ & $\mathrm{No}=5$ \\
\hline Analyses: Unit of allocation & Practice & Practice \\
\hline Unit of analysis & Individual & Individual \\
\hline Are the statistical methods appropriate for the study design? & Yes $=1$ & Yes $=1$ \\
\hline $\begin{array}{l}\text { Is the analysis performed by intervention allocation status (ITT) rather than } \\
\text { actual intervention received? }\end{array}$ & Yes $=1$ & Yes $=1$ \\
\hline
\end{tabular}

Table 4 Summary of Global rating for Quality using EPHPP Quality Assessment tool

\begin{tabular}{lll}
\hline Component & Becker et al. [30] & Rubak et al. [31] \\
\hline Selection Bias & Weak & Weak \\
Study Design & Strong & Strong \\
Confounders & Strong & Strong \\
Blinding & Moderate & Moderate \\
Data Collection Methods & Strong & Strong \\
Withdrawals and Dropouts & Strong & Strong \\
Global rating & Moderate & Moderate \\
\hline
\end{tabular}

Criteria for global rating; 1 . Strong $=$ no weak ratings 2 . Moderate $=$ one weak rating, 3 . Weak $=$ two or more weak ratings self-management is a core element of person-centered healthcare in family practice and given the volume of published material on patient self-management.

This review shows that when health professionals undergo training in empowering patients for self-management of chronic conditions, it is possible to achieve improvement in patients' self-efficacy, autonomy and motivation to change, functional capacity, pain free days and quality of life.

One study [30] demonstrated improvement in functional capacity, quality of life scale and a greater number of pain free days reported by patients after six months and after 12 months among those whose primary care 


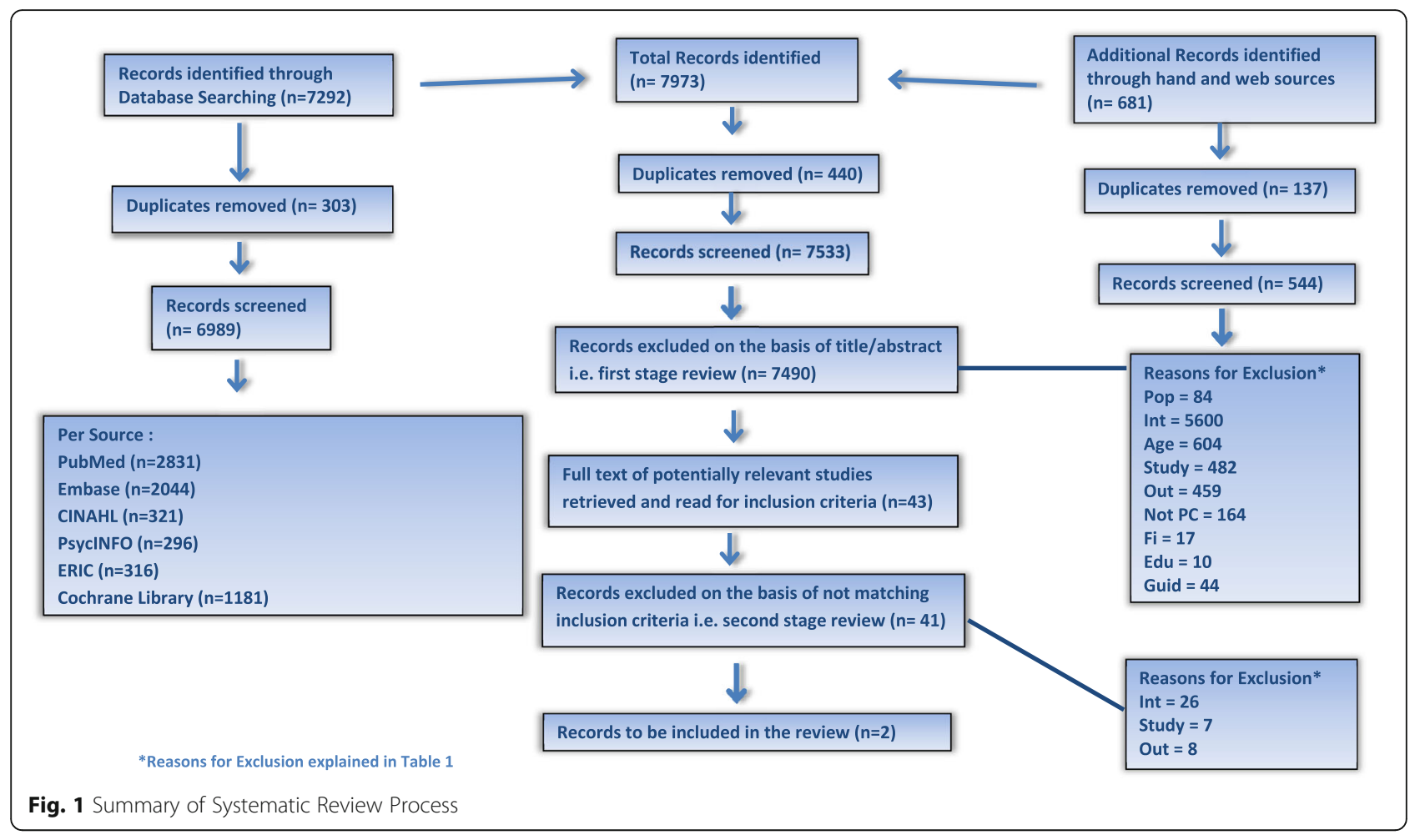

clinicians had been given training in motivational interviewing techniques. A second study [31] showed that patients of the health professionals who participated in specific training programmes were more motivated to change behaviours and were more autonomous in their choice of behavioural changes compared to a control group. These patients were significantly more aware of the importance of controlling their diabetes for specific factors, and had a higher level of perception of having received specific advice from their GP on healthy behaviour changes.

\section{Limitations of the review}

Despite much literature on patient self-management in chronic disease, focussing on whether training health professionals regarding patient self-management improves patient outcomes, resulted in only two articles being eligible for inclusion in this systematic review. We are aware that some additional studies have been published more recently on self-management that were outside the chosen search period of this review. We plan to update this review in 2018. However, we feel it is important to publish the findings of this first phase review to highlight that, despite a vast volume of literature on one topic, evidence of impact on patient outcomes is largely lacking during the study period despite the publicity and interest in patient empowerment for self-management in the years leading up to its official inclusion in the European definition in 2011.
The small number of studies included and the range of outcome measures therein made concrete conclusions impossible, both papers describe positive outcomes from teaching motivational interviewing skills to clinicians, but we do not yet know if other approaches would be equally or more effective. The two studies did not report effect sizes, further complicating the interpretation of results. A further limitation is that only articles in English were included, based on available resources.

A total of 1643 patients, 191 clinicians and 164 practices were involved in these studies in two European countries, however further research on this topic is also needed to clarify if other factors are effective in improving patient outcomes other than those involving time constrained clinicians in general practice.

\section{Interpretation of findings in the context of existing evidence}

This review has given us concrete evidence of the lack of studies in the English language on improving patient outcomes through training primary care clinicians in patient self-management. Previous studies focus on patient education, group discussion among patients, shared experiences and unstructured acquisition of knowledge during clinical encounters or through leaflets and brochures $[16,25,32,33]$ rather than on assessing the specific effect of specific clinician training on patient outcomes in this setting. Primary care professionals have a longitudinal relationship with patients in the patient's 
Table 5 Study Description

\begin{tabular}{|c|c|c|c|c|c|}
\hline $\begin{array}{l}\text { Author } \\
\text { Country } \\
\text { Year }\end{array}$ & Design/Intervention & $\begin{array}{l}\text { Analysis (unit of } \\
\text { analysis/power } \\
\text { calculation) }\end{array}$ & $\begin{array}{l}\text { Objective measurement/ } \\
\text { Follow-up period }\end{array}$ & $\begin{array}{l}\text { Successful Educational } \\
\text { Aspects }\end{array}$ & Limitations \\
\hline $\begin{array}{l}\text { Becker } \\
\text { et al. } \\
\text { Germany } \\
2008 \text { [30] }\end{array}$ & $\begin{array}{l}\text { Cluster RCT with } 2 \\
\text { intervention arms and } 1 \\
\text { control arm. } \\
\text { Control arm guidelines only } \\
\text { (C). } \\
\text { Two intervention groups - } \\
\text { both received a } \\
\text { multifaceted general } \\
\text { practitioner education and } \\
\text { Gl one additionally received } \\
\text { motivational counselling } \\
\text { training for practice nurses } \\
\text { (MC) } \\
\text { Gl and MC trained in using } \\
\text { LBP guideline for the } \\
\text { DEGAM - } 4 \text { modules: } 3 \\
\text { interaction seminars; } \\
\text { information given on local } \\
\text { facilities; } 2 \text { individual } \\
\text { educational visits by study } \\
\text { nurses. In MC group, } 2 \\
\text { nurses per practice } \\
\text { received } 2 \text { full day } \\
\text { workshops and 1-3 } \\
\text { supervision sessions and } \\
\text { study coordinators } \\
\text { contacted the nurses } \\
\text { regularly. }\end{array}$ & $\begin{array}{l}\text { Unit of analysis is } \\
\text { the patient. } \\
\text { Power calculation } \\
\text { for small effects. } \\
\text { Drop out } \\
\text { analyses included. }\end{array}$ & $\begin{array}{l}\text { Main Outcome: Hannover } \\
\text { Functional Ability } \\
\text { Questionnaire for } \\
\text { Measuring Back Pain } \\
\text { Related Functional } \\
\text { Limitations. Secondary } \\
\text { outcomes: Freiburg } \\
\text { Questionnaire on Physical } \\
\text { Ability; Korffs severity of } \\
\text { chronic pain scale; Euro } \\
\text { Quality of life questionnaire; } \\
\text { Fear Avoidance Beliefs } \\
\text { questionnaire; } \\
\text { Days of sick leave. } \\
\text { Follow-up: } 6 \text { and } \\
12 \text { months. }\end{array}$ & $\begin{array}{l}\text { After } 6 \text { months: functional } \\
\text { capacity improvement more } \\
\text { pronounced in intervention } \\
\text { groups and significantly so } \\
\text { for adjusted differed } \\
\text { between MC and C groups; } \\
\text { both Gl and MC patients } \\
\text { significantly less days in pain } \\
\text { during previous } 6 \text { months } \\
\text { and less patients in } \\
\text { intervention groups } \\
\text { indicated suffering } \\
\text { permanent pain than C } \\
\text { patients. } \\
12 \text { months: more } \\
\text { pronounced reduction in } \\
\text { days in pain in Gl and MC } \\
\text { compared to C group. } \\
\text { Patients in MC group } \\
\text { showed significant } \\
\text { improvement in quality of } \\
\text { life. Clinical guidelines } \\
\text { improve outcome; physician } \\
\text { education has a little } \\
\text { benefit, motivational } \\
\text { interviewing adds slightly } \\
\text { more benefit but probably } \\
\text { only useful for some } \\
\text { patients. }\end{array}$ & $\begin{array}{l}\text { Inclusion rate } 44 \% \text { which } \\
\text { might be due to selection } \\
\text { bias. Patient sample had } \\
\text { wide representation of pain } \\
\text { qualities and quantities as } \\
\text { well as different } \\
\text { motivational stages for } \\
\text { behaviour change, so } \\
\text { individual differences in } \\
\text { effects of interventions may } \\
\text { be masked. Included } \\
\text { patients may have had } \\
\text { lower levels of pain, higher } \\
\text { physical activity and } \\
\text { readiness for change than } \\
\text { general LBP patients in } \\
\text { general - may reduce } \\
\text { external validity of the } \\
\text { study. Validity of the FQPA } \\
\text { for a primary care sample } \\
\text { with low disability may be } \\
\text { insufficient and may limit its } \\
\text { discriminative power. } \\
\text { Insufficient counselling } \\
\text { sessions to draw } \\
\text { conclusions. }\end{array}$ \\
\hline $\begin{array}{l}\text { Rubak } \\
\text { et al. } \\
\text { Denmark } \\
2009 \text { [31] }\end{array}$ & $\begin{array}{l}\text { One year follow up of an } \\
\text { RCT/1.5 day residential MI } \\
\text { course for GPs and a half } \\
\text { day follow up twice during } \\
\text { first year. } \\
\text { Both I and C groups had } \\
\text { half day course on } \\
\text { intensive treatment of type } \\
2 \text { diabetes. }\end{array}$ & $\begin{array}{l}\text { Unit of analysis is } \\
\text { the patient. } \\
\text { Sample size } \\
\text { determined by } \\
\text { power analysis. }\end{array}$ & $\begin{array}{l}\text { Health Care Climates } \\
\text { Questionnaire; Treatment } \\
\text { Self-regulation Question- } \\
\text { naire; Diabetes Illness Rep- } \\
\text { resentation Questionnaire; } \\
\text { Summary of Diabetes self- } \\
\text { care activities. } \\
\text { Follow-up: } 12 \text { months. }\end{array}$ & $\begin{array}{l}\text { Patients in I group } \\
\text { significantly more } \\
\text { autonomous in their choice } \\
\text { of action towards } \\
\text { behavioural changes and } \\
\text { more motivated to change } \\
\text { behaviours; also significantly } \\
\text { more aware of the } \\
\text { importance of controlling } \\
\text { their diabetes for specific } \\
\text { factors. }\end{array}$ & $\begin{array}{l}\text { Not blinded at } \\
\text { randomization. No baseline } \\
\text { data; Patients were newly } \\
\text { diagnosed so there was no } \\
\text { change behaviour and no } \\
\text { statements regarding } \\
\text { diabetes at baseline. No } \\
\text { blinding of behavioural } \\
\text { changes - Hawthorne effect } \\
\text { may exist; but if so, existed } \\
\text { in both groups. Involvement } \\
\text { in study may have } \\
\text { influenced and diminished } \\
\text { effect of Ml. }\end{array}$ \\
\hline
\end{tabular}

own community, are accessible to patients, and though contacts are intermittent, there is coordination and continuity of care. This review suggests that teaching motivational interviewing skills to health professionals in primary care may improve self-efficacy and quality of life in their patients, compared to those patients of clinicians who did not participate in this training. It suggests that the addition of motivational interviewing techniques to usual care may have added benefit for patients over usual care in the primary care setting, however further research is needed to identify if other educational interventions or skills are useful.

\section{Implications for further research}

Further research is needed to distil the specific techniques to empower patients for self-management [34]; to explore and define the various aspects of the concept of patient empowerment [35]; and the variety of approaches that can be taken by primary care physicians to support patients to self monitor and make decisions about their chronic condition. We also need to identify and address potential barriers for self-management in patients [36].

Patients with chronic conditions interact over time with many professionals in primary and secondary care. There are many other interventions that may help to improve patient self-management, (for example group education, health coaching, telemedicine, e-health, media led interventions, voluntary associations, sports organisations and community group activities). Additional factors having a potential impact on successful outcomes include patient preferences for individual or group 
interventions, and patients' values, goals, level of education and literacy. Patients have increasingly easy and direct access to online resources. We need research to guide both clinicians and patients to know which methods are best used in which settings [37], and which methods are not suited to particular settings. Careful designs and methods need to be used in future studies to assess the impact of such factors on measuring the outcomes of patient self-management including the Hawthorne effect and language bias. Appropriate assessment tools are required taking account of the integrative model of change appropriate in different settings [38].

Studies are also needed on evidence for the feasibility of training health professionals in patient self-management approaches including efficient use of resources such as time, people and finance, as research into the value and effectiveness of the various methods that can be used to "empower patients" is still in its infancy [37].

We also need to promote the inclusion of validated scales and instruments in future research for measurement and comparison of patient outcomes in chronic conditions.

\section{Conclusions}

Effective training for healthcare staff in patient self-management support is important in the context of patient centred care, patient outcomes, health care economics, strategy and delivery of healthcare on a global perspective.

This review suggests that primary care health professionals can help to harness patients' capacity to contribute to improvement of their own health outcomes. Despite increasing literature on patient self-management and on health professional training on this topic, the evidence is very limited on measured patient health outcomes up to two years after patient self-management was incorporated into the WONCA definition of general practice. We plan to undertake a follow-up systematic review to establish if this changes over time or if further research is needed to assure health professionals and policy makers that patient self-management is a worthwhile and effective aspect of general practice.

\section{Additional file}

Additional file 1: Search terms and search example. (DOCX 15 kb)

\footnotetext{
Abbreviations

CCM: Chronic care model; EQUIP: European Society for Quality and Safety in General Practice / Family Medicine; Gl: Guideline implementation; GP/ FM: General Practitioner/ Family Physician; MIT: Motivational interviewing techniques; NCD: Non-communicable disease; PSM: Patient selfmanagement; RCT: Randomised controlled trial; WHO: World Health Organisation; WONCA: World Organization of National Colleges, Academies and Academic Associations of General Practitioners/Family Physicians
}

\section{Acknowledgements}

We acknowledge the contributions of Dr. Ernesto Mola (Scientific Interdisciplinary Association of Both Family and Community Medicine (ASSIMEFAC), Lecce, Italy) and Associate Professor John Litt (Flinders University, Adelaide, Australia and Deputy Chair of National Quality Committee RACGP) on the theories and concepts of patient empowerment for self-management which encouraged EQuiP to conduct this research.

\section{Funding}

Funding for this project was provided by WONCA Europe through its 20th Anniversary Fund and supplemented by the authors' institutions. The WONCA Europe Executive Board had no role in the design of the study, data collection, analysis, interpretation of data or in writing the manuscript.

\section{Availability of data and materials}

No administrative permissions were required for accessing databases as all were available to the authors.

\section{Authors' contributions}

AR participated in the original protocol, review of articles, the write up of the paper and the steering group and reviewed the final version of the paper. SB participated in the original protocol, review of articles and reviewed the final version of the paper. GD participated in the original protocol, the literature search, and reviewed the final version of the paper. PP participated in the original protocol, the literature search, and reviewed the final version of the paper. JG participated in the review of articles, and the steering group and reviewed the final version of the paper. IK participated in the steering group and reviewed the final version of the paper. SS participated in the steering group and reviewed the final version of the paper. TE participated in the steering group and reviewed the final version of the paper. CC participated in the original protocol, review of articles, the write up of the paper, the steering group and reviewed the final version of the paper. All authors read and approved the final manuscript.

Ethics approval and consent to participate

Not applicable as this is a systematic review with no primary data collection.

Consent for publication

Not applicable as this is a systematic review with no primary data collection.

\section{Competing interests}

The authors declare that they have no competing interests.

\section{Publisher's Note}

Springer Nature remains neutral with regard to jurisdictional claims in published maps and institutional affiliations.

\section{Author details}

${ }^{1}$ Irish College of General Practitioners, 4-5 Lincoln Place, Dublin 2, Ireland. ${ }^{2}$ Institute of General Practice and Family Medicine, University Hospital, LMU, Munich, Germany. ${ }^{3}$ University of Helsinki, EBM Guidelines, Duodecim Medical Publications Ltd, Helsinki, Finland. ${ }^{4}$ Royal College of Surgeons in Ireland, Dublin, Ireland. ${ }^{5} \mathrm{GP}$ Copenhagen, Copenhagen, Denmark.

Received: 16 March 2018 Accepted: 13 September 2018 Published online: 29 September 2018

\section{References}

1. WONCA Europe. The European Definition of General Practice/Family Medicine WONCA Europe 2011 Edition. Available at: http://www.wonca europe.org/sites/default/files/documents/Definition\%203rd\%20ed\%20 2011\%20with\%20revised\%20wonca\%20tree.pdf. Accessed 31 Jan 2018.

2. Grüninger U, Kissling B. Die Hausarztmedizin als eigene Disziplin und als Spezialgebiet (family medicine - a specialty of its own). Primary Care. 2005; 5(11):269-71.

3. Mola E, De Bonis JA, Giancane R. Integrating patient empowerment as an essential characteristic of the discipline of general practice/family medicine. Eur J Gen Pract. 2008;14(2):89-94.

4. Patient Empowerment in Chronic Conditions - Wonca Europe (PECC-WE). The WONCA Anniversary Research Fund 2012-2015 project. Available at: 
http://equip.woncaeurope.org/tools/pecc-we-patient-empowerment/ patient-empowerment Accessed 13 Sept 2016.

5. World Health Organization. Innovative care for chronic diseases. Building blocks for action. Global Report. Geneva: WHO; 2002. Available at: http://www.who.int/ chp/knowledge/publications/icccglobalreport.pdf. Accessed 11 Nov 2015.

6. World Health Organization. Global status report on Non-Communicable Diseases 2014. Geneva: WHO; 2014. Available at: http://www.who.int/nmh/ publications/ncd-status-report-2014/en/. Accessed 11 Nov 2015.

7. Wagner E, Austin B, Von Korff M. Organising care for patients with chronic illness. Millbank Quarterly. 1996;74(4):511-44.

8. Lorig KR, Holman H. Self-management education: history, definition, outcomes, and mechanisms. Ann Behav Med. 2003;26(1):1-7.

9. Battersby M, Lawn S. Capabilities for supporting prevention and chronic condition self-management: a resource for educators of primary health care professionals. Flinders University, Adelaide: Australian Government Department of Health and Ageing; 2009.

10. Gruman J, Von Korff M. Indexed bibliography on self-management for people with chronic diseases. Washington, DC: Center for Advancement in Health; 1996.

11. Parlour R, Slater PF. An evaluation of the effectiveness of a selfmanagement Programme. Office of the Nursing and Midwifery Services Director, Health Service Executive: Dublin; 2011.

12. Bradley PM, Lindsay B. Care delivery and self-management strategies for adults with epilepsy. Cochrane Database of Syst Rev. 2008;23(1):CD006244.

13. Deakin T, McShane CE, Cade JE, Williams RD. Group based training for selfmanagement strategies in people with type 2 diabetes mellitus. Cochrane Database of Syst Rev. 2005;18(2):CD003417.

14. Holman H, Lorig K. Patient self-management: a key to effectiveness and efficiency in care of chronic disease. Public Health Rep. 2004;119(3):239-43.

15. Ofman JJ, Badamgarav E, Henning JM, Knight K, Gano AD Jr, Levan RK, et al. Does disease management improve clinical and economic outcomes in patients with chronic diseases? A systematic review. Am J Med. 2004;117(3):182-92.

16. Marks R, Allegrante JP, Lorig K. A review and synthesis of research evidence for self-efficacy-enhancing interventions for reducing chronic disability: implications for health education practice (part II). Health Promot Pract. 2005;6(2):148-56.

17. Du S, Yuan C. Evaluation of patient self-management outcomes in health care: a systematic review. Int Nurs Rev. 2010;57(2):159-67.

18. Lorig KR, Sobel DS, Stewart AL, Brown BW Jr, Bandura A, Ritter P, et al. Evidence suggesting that a chronic disease self-management program can improve health status while reducing hospitalization: a randomized trial. Med Care. 1999:37(1):5-14

19. Bodenheimer T, Wagner EH, Grumbach K. Improving primary care for patients with chronic illness. JAMA. 2002;288(14):1775-9.

20. Muenchberger $H$, Kendall E. Predictors of preventable hospitalization in chronic disease: priorities for change. J Public Health Policy. 2010; 31(2):150-63.

21. Wagner EH, Austin BT, Davis C, Hindmarsh M, Schaefer J, Bonomi A. Improving chronic illness care: translating evidence into action. Health Aff (Millwood). 2001;20(6):64-78

22. Bodenheimer T, Wagner EH, Grumbach K. Improving primary care for patients with chronic illness: the chronic care model, part 2. JAMA. 2002; 288(15):1909-14.

23. Litt J, Rochfort A, Collins C, O'Riordan M. Patient self-Management in Chronic Conditions. Dublin: Irish College of General Practitioners; 2011

24. Dennis CL. Peer support within a health care context: a concept analysis. Int J Nurs Stud. 2003:40(3):321-32.

25. Lawn S, Schoo A. Supporting self-management of chronic health conditions: common approaches. Patient Educ Couns. 2010;80(2):205-11.

26. Jordan JE, Briggs AM, Brand CA, Osborne RH. Enhancing patient engagement in chronic disease self-management support initiatives in Australia: the need for an integrated approach. Med J Aust. 2008;189(10 Suppl):S9-S13.

27. Moher D, Liberati A, Tetzlaff J, Altman DG. Preferred reporting items for systematic reviews and meta-analyses: the PRISMA statement. Ann Intern Med. 2009;151(4):264-9.

28. Collins C, Rochfort A, Beirne S, Doran G, Patton P. The effectiveness of educational interventions for primary care health professionals designed to improve self-management in patients with chronic conditions. PROSPERO. 2013:CRD42013004418 http://www.crd.york.ac.uk/PROSPERO/display_record. asp?ID=CRD42013004418. Accessed 13 Nov 2015.

29. Thomas H. Quality assessment tool for quantitative studies. McMaster University, Toronto: Effective Public Health Practice Project; 2003.
30. Becker A, Leonhardt C, Kochen MM, Keller S, Wegscheider K, Baum E, et al. Effects of two guideline implementation strategies on patient outcomes in primary care: a cluster randomized controlled trial. Spine (Phila Pa 1976). 2008;33(5):473-80. https://doi.org/10.1097/BRS.0b013e3181657e0d.

31. Rubak S, Sandbaek A, Lauritzen T, Borch-Johnsen K, Christensen B. General practitioners trained in motivational interviewing can positively affect the attitude to behaviour change in people with type 2 diabetes. One year follow-up of an RCT, ADDITION Denmark. Scand J Prim Health Care. 2009; 27(3):172-9. https://doi.org/10.1080/02813430903072876.

32. Solberg HS, Steinsbekk A, Solbjør M, Granbo R, Garåsen H. Characteristics of a self-management support programme applicable in primary health care: a qualitative study of users' and health professionals' perceptions. BMC Health Serv Res. 2014;14:562.

33. NHS. Expert Patients Programme (EPP). 2014. Available at: http://www.nhs.uk/ NHSEngland/AboutNHSservices/doctors/Pages/expert-patients-programme. aspx. Accessed 16 Nov 2015.

34. Lenzen SA, Daniëls R, van Bokhoven MA, van der Weijden T, Beurskens A. Setting goals in chronic care: Shared decision making as self-management support by the family physician. Eur J Gen Pract. 2015;21(2):138-44. https:// doi.org/10.3109/13814788.2014.973844 Epub 2014 Dec 26.

35. Bravo P, Edwards A, Barr PJ, Scholl I, Elwyn G, Mc Allister M, Cochrane Healthcare Quality Research Group, Cardiff University. Conceptualising patient empowerment: a mixed methods study. BMC Health Serv Res. 2015; 15:252. https://doi.org/10.1186/s12913-015-0907-z.

36. Eikelenboom N, van Lieshout J, Jacobs A, Verhulst F, Lacroix J, van Halteren A, Klomp M. Smeele I, Wensing M. Effectiveness of personalised support fro self-management in primary care: a cluster randomised controlled trial. $\mathrm{Br} J$ Gen Pract. 2016;66(646):e354-61. https://doi.org/10.3399/bjgp16X684985 Epub 2016 Apr 14

37. Grol R. Improving the quality of medical care: building bridges among professional pride, payer profit, and patient satisfaction. JAMA. 2001;286: 2578-85.

38. Prochaska JQ, DiClemente CC. Transtheoretical therapy: toward a more integrative model of change. Psychotherapy. 1982;20:161-73.

\section{Ready to submit your research? Choose BMC and benefit from:}

- fast, convenient online submission

- thorough peer review by experienced researchers in your field

- rapid publication on acceptance

- support for research data, including large and complex data types

- gold Open Access which fosters wider collaboration and increased citations

- maximum visibility for your research: over $100 \mathrm{M}$ website views per year

At $\mathrm{BMC}$, research is always in progress.

Learn more biomedcentral.com/submissions 